\title{
POSTPRINT
}

Bernard, P., \& Carayol, M. (2015). A commentary on the importance of controlling for medication use within trials on the effects of exercise on depression and anxiety. Mental Health and Physical Activity, 9, 10-15.

https://doi.org/10.1016/j.mhpa.2015.07.001

\section{A commentary on the importance of controlling for medication use within trials on}

the effects of exercise on depression and anxiety

\author{
Bernard. $\mathrm{P}^{\mathrm{a}, \mathrm{b}, \mathrm{c}}$, Carayol $\mathrm{M}^{\mathrm{d}}$. \\ a Université Laval Cancer Research Center,Québec, Québec, Canada \\ b School of Psychology, Université Laval, Québec, Québec, Canada \\ ${ }^{\circ} \mathrm{CHU}$ de Québec - Université Laval Research Center, Québec, Québec, Canada \\ d INSERM UMR 1027, Paul Sabatier University, 37 allées Jules Guesde, F-31073 Toulouse, \\ France
}

Correspondence concerning this article should be addressed to : Paquito Bernard, Cancer Research Center, Laval University, 11 Côte du Palais, Québec, Québec, Canada, G1R2J6

\section{Funding}

P. Bernard is supported by a postdoctoral fellowship from the Fonds de Recherche-Santé Québec and Programme Psychosocial Oncology Research Training.

\section{Acknowledgement}

The authors wish to express their gratitude to reviewers and Gregory Moullec, Josée Savard, Emmanuel d'Estanque. 
Meta-analyses have shown that exercise interventions reduce depressive (Herring, Puetz, O'Connor, \& Dishman, 2012, Ekkekakis, 2015) and anxiety symptoms (Herring, O'Connor, \& Dishman, 2010) among patients with a clinical mental health condition and also among those with physical health conditions (e.g.,COPD (Coventry et al., 2013), heart failure (Tu et al., 2014), multiple sclerosis (Dalgas, Stenager, Sloth, \& Stenager, 2014), and breast cancer (Carayol et al., 2013), but the role of medication use in understanding these effects is not clear.

The aims of this commentary are to (1) identify the potential interactive effects of exercise with anxiety/depression medications, based on mechanistic or observational studies, (2) describe how studies dealt with use of antidepressant or anxiolytic participants' medications in their study design and analyses, based on a narrative review of Randomized Controlled Trials (RCTs), and (3) consider the implications for future research for assessing the use of medications within trials and using this information in analyses.

\section{Which types of interaction could occur between exercise and medications?}

Mechanistic or observational studies indicate four types of interactive effects of exercise with anxiety and depression drugs that could bias effect estimates of exercise on psychological symptoms in RCTs:

\section{(a) A synergistic/additive effect}

An animal investigation has suggested that antidepressants and exercise could act synergistically to upgrade brain-derived neurotrophic factor level which has been negatively associated with depression (RussoNeustadt, Beard, \& Cotman 1999). Based on murin and humans models, repeated physical exercise and prolonged antidepressant treatment could be considered to engage the same neuroprotective pathways (see details in Chen, 2013), suggesting an additive effect of exercise and antidepressant. In addition, a reduction in blood serotonin could occur after exercise among healthy adults, suggesting a higher retention of serotonin in the brain and then a decrease of depression level after exercise (Wipfli et al., 2009).

\section{(b) An antagonistic effect}

In contrast, an antagonistic effect may also exist between exercise and antidepressants. Indeed, Selective Serotonin Reuptake Inhibitor (SSRI) could be decreased with motor activity (based on murin studies) (Marlatt, Lucassen, \& van Praag, 2010). In humans, an increased risk of muscle injuries has been reported with SSRI treatment (Labotz et al., 2013).

\section{(c) A behavioral effect}

Antidepressant and anxiolytics could moderate the efficacy of exercise through exercise adherence. Although a high depression score is a well-identified predictor of poor adherence (Jette et al., 1998), findings about the relationship of antidepressant and anxiolytic treatments with exercise adherence are scarce and 
inconsistent. Prescribed antidepressant medication was a major predictor of poor adherence rate or drop-out in individuals participating in an exercise cardiac rehabilitation program (Lautsen, Hjortal, \& Pertersen, 2013; Marzolini, Brooks, \& Oh, 2008), whereas in an interventional RCT designed for weight loss in postmenopausal women, exercise intervention adherence did not differ between antidepressant users and non-users (Imayama et al., 2013). Comorbid conditions (i.e., higher anxiety and poorer life satisfaction) were also associated with higher dropout rate in middle-aged adults with MDD (Herman et al., 2002).

\section{(d) Health status of participants}

The use of antidepressant and or anxiolytic drugs may also reflect differential health status. In the Australian population, the individuals who take one of these two medications were likely to have more comorbidities (e.g., diabetes, cardiovascular disease, cancer, arthritis) than non-users (Atlantis et al. 2012). Such comorbidities have been associated with greater functional limitations (Sevick et al., 2007) and poorer exercise adherence rates (Tobi, Estacio, Yu, Renton, \& Foster, 2012). Furthermore, these medications may impair the efficacy of concomitant treatment. For instance, Breitbart (2011) suggested that antidepressants (inhibitors of CYP2D6) used concurrently with tamoxifen may reduce the clinical efficacy of tamoxifen among cancer patients.

\section{Did RCTs testing the effects of exercise on depression and anxiety considered these possible}

\section{interactions?}

We performed a narrative review of literature to examine whether a potential interaction effect of antidepressant/anxiolytic medication with exercise has been identified in previous RCTs. Studies cited in published systematic reviews were included in the present review if they met the following PICOS criteria. Participants were adults with or without depressive/anxiety disorders. Interventions examined the effects of physical exercise (supervised or home-based) and reported a medication arm or antidepressant/anxiolytic medication use during exercise intervention. Control groups were usual care, exercise (other form), other treatment or active control condition. Outcomes were depression/anxiety score (using psychometric instruments) or results from standardized psychiatric interview. Only published RCTs were included.

\section{Antidepressants in Exercise RCTs}

Six systematic reviews with meta-analyses focusing on the effects of exercise interventions on depression were identified. The reviews with 39 (Cooney et al., 2013), 90 (Herring et al., 2012), 14 (Perraton et al., 2010), 8 (Robertson, Robertson, Jepson, \& Maxwell, 2012), 58 (Rethorst et al., 2010), and 13 RCTs (Mura, 
Moro, Patten, \& Carta, 2014) were screened, and 24 were selected. The studies identified are presented in the following sections: (a) RCTs with exercise and medications arms, (b) RCTs with an exercise arm including only participants with antidepressant treatment, (c) RCTs with an exercise arm describing participants' use of antidepressant at baseline.

\section{(a) RCTs with exercise and medications arms}

A 3-armed RCT compared a 16-week intervention involving exercise combined with sertraline (i.e. SSRI) vs. exercise vs. sertraline in older adults $(N=156)$ with MDD (Blumenthal et al., 1999). Patients in combined treatments received simultaneously the same medication and exercise described below. Sertraline was provided by psychiatrists and was initiated with $50 \mathrm{mg}$ daily. Participants were evaluated (therapeutic responses and sides effects) five times during the treatment. Participants in exercise arms attended three weekly supervised aerobic exercise sessions of 45 minutes. Twenty percent of included patients dropped out before the end of intervention. The exercise adherence rates were nearly $90 \%$ of sessions in exercise or combined condition. The depression score did not differ between groups at the end of treatment period (Blumenthal et al., 1999). However, some differences between groups were seen for the timing of depression decrease. Participants in the sertraline arm exhibited a faster therapeutic response within the first few weeks compared to other groups and, participants with initial mild depressive symptoms (Hamilton Rating Scale for Depression, HAMD score between 13 to 18 ) receiving the combined intervention showed an earlier decrease of depression level compared to exercise or medication only.

Three other 3-armed RCTs compared exercise vs. SSRI vs. placebo/usual care among adults with depressive disorders (Blumenthal et al., 2007, 2012a; Brenes et al., 2007). Two studies found a significant superiority of the aerobic exercise and SSRI conditions over pill placebo (without difference between exercise and SSRI arms) to decrease depression level or remission rate (Blumenthal et al., 2007, 2012a). The findings suggested also a possible superiority of exercise over sertraline in the context of more baseline exacerbate depression severity. However, in the study of Brenes et al. (2007) including 37 older adults with elevated depressive symptoms, intervention conditions (i.e., exercise vs. SSRI) were not significantly superior to placebo (i.e., usual care) on HRDS and Geriatric Depression Scales scores; a lack of power due to small size sample could be responsible for this negative result. In a 4-armed RCTs, Blumenthal et al. (2007) assessed the efficacy of aerobic exercise (home based vs. supervised) vs. sertraline vs. pill placebo on depression among 202 adults with current MDD. They found a significant superiority of active treatments over placebo for remission rates but not for HAMD continuous scores. For both outcomes, no differences 
were obtained between aerobic exercise (home based and supervised) and sertraline interventions. A more recent RCT compared supervised aerobic exercise vs. sertraline vs. pill placebo in 101 patients with coronary heart disease and elevated depressive symptoms (Blumenthal et al., 2012a). Exercise and sertraline treatment were found to be superior over placebo to decrease HRDS scores at the end of intervention. No statistical differences were found between active treatments. Sub-analyses among patients initially meeting the criteria for MDD suggested a possible superiority of exercise over sertraline and placebo for remission rates $(40 \%, 20 \%, 0 \%$ respectively).

\section{(b) RCTs with an exercise arm including exclusively participants with antidepressant}

\section{treatment}

Six RCTs (exercise vs. health education or relaxation or usual care or light therapy) involved participants all with antidepressant treatment, irrespectively of their randomization, but no ancillary analyses were carry out to assess a differential effect of type or dose of antidepressant on depression due to small sample sizes (Knubben et al., 2007; Martiny et al., 2012; Mather et al., 2002; Mota-Pereira et al., 2011; Pilu et al., 2007; Schuch, Vasconcelos-Moreno, Borowsky, \& Fleck, 2011). Two of them included patients with treatment resistant depressive disorders and controlled the duration of antidepressant treatment at baseline (MotaPereira et al., 2011, Mather et al., 2002).

\section{(c) RCTs with an exercise arm describing participants' use of antidepressant at baseline}

The use of antidepressant at baseline was described in 15 RCTs (Armstrong \& Edwards, 2003, 2004; Blumenthal et al., 2005; 2012b; Bombardier et al., 2013; Chalder et al., 2012; Chu, Buckworth, Kirby, \& Emery, 2009; Craft, Freund, Culpepper, \& Perna, 2007; Foley et al., 2008; Gary, Dunbar, Higgins, Musselman, \& Smith, 2010; Martinsen et al., 1985, 1989; Neidig, Smith, \& Brashers, 2003; Piette et al., 2011; Veale et al., 1992; Williams \& Tappen, 2008). Among participants with depressive disorders the rates of medications at baseline varied between 29\% (Gary et al., 2010) and 57\% (Chalder et al., 2012; Piette et al., 2011). Among these RCTs, seven included specific participants: patients with heart failure (Gary et al., 2010), postpartum women (Armstrong \& Edwards, 2003, 2004), adults with multiple sclerosis (Bombardier et al., 2013), adults with diabetes (Piette et al., 2011), primary care patients (Chalder et al., 2012). Among those without depressive disorders, 22\% (Blumenthal et al., 2005, 2012b), 36\% (adults with Alzheimer's disease) (Williams \& Tappen, 2008) and 20\% (Neidig et al., 2003) had medications at baseline.

In summary, none of these studies reported a sensitivity analysis on the effect of exercise in participants with antidepressant medication. Very little information was available about the dose and subtype of antidepressant in selected RCTs. These details were given in only one multicenter RCT with a large 
sample $(N=2322)$ that examined the impact of exercise within a subset of patients with elevated depressive symptoms (Blumenthal et al., 2012b). In the included RCTs, none found an initial difference of baseline antidepressant rate between groups and, only four RCTs carried out their statistical analyses controlling for baseline antidepressant rates (Blumenthal et al., 2012b; Bombardier et al., 2013; Chalder et al., 2012; Gary et al., 2010). Adherence to antidepressant was described in only one investigation (Piette et al., 2011).

\section{Anxiolytics in Exercise RCTs}

Two systematic reviews and meta-analyses focusing on the effects of exercise interventions on anxiety were identified. The reviews with 40 (Herring et al., 2010) and 12 (Stonerock, Hoffman, Smith, \& Blumenthal, 2015) RCTs were screened and two studies were selected, both involving adults with panic disorders (Brooks et al., 1998; Wedekin et al., 2010).

One RCT compared exercise alone vs. clomipramine alone vs. pill placebo (Brooks et al., 1998). Both exercise and clomipramine resulted in a significant clinical improvement compared to placebo but no difference was seen in the effects of exercise and clomipramine. The other RCT included 4 arms participants $(N=75)$ received either: exercise+paroxetine vs. relaxation+paroxetine vs. exercise+pill placebo vs. relaxation+pill placebo (Wedekin et al., 2010). A statistically significant decrease of Panic and Agoraphobia Scale score was found in all treatment groups without any differences between them. Clinical Global Impression scores were also significantly improved for the 4 treatment arms compared to placebo, and the benefits for exercise+paroxetine and relaxation+paroxetine were significantly superior to relaxation+placebo.

We also examined if any RCT that compare exercise vs. no exercise included in the above mentioned reviews had attempted to control for medication use either at baseline or during the exercise intervention through sensitivity analysis.

Finally, although large-scale cohorts of breast cancer patients $11-30 \%$ report using antidepressant (Azzone, Frank, Pakes, Earle, \& Hassett, 2009; Ng, Boks, Smeets, Zainal, \& de Wit, 2013) and 25-30\% use anxiolytics (Azzone et al., 2009; Coyne, Palmer, Shapiro, Thompson, \& DeMichele, 2004), it is worth noting that in a recent systematic review of 20 RCTs to test the effects of exercise on anxiety and depression in breast cancer patients (see details in Carayol, Delpierre, Bernard, \& Ninot, 2015), we were not able to test the moderation effect of medication as only one study reported information about anxiolytics and/or antidepressants use.

In summary, no clear difference was observed in the effect of exercise alone and antidepressant/ anxiolytic medications alone on depression or anxiety. Only one RCT has tested the combination of exercise and 
medication (Blumenthal et al., 1999) and reported no incremental benefit of medication with exercise. In addition, in the analysis of the effects of exercise on depression or anxiety, no study involved an analysis to test how the effects of exercise were influenced by medication use.

\section{Implications for future research}

The potential interactive effects we highlighted between exercise and medication use have led us to propose several courses of actions that may improve our understanding of the true effects of exercise on mental health, and specifically depression and anxiety.

(1) More precise information should be collected and displayed in ongoing and future RCTs focusing on the efficacy of exercise on depression/anxiety. A list of useful criteria related to participants, intervention and comparison (drawn from PICO guidelines (Liberati et al., 2009)) for the design and report of future RCTs is presented in Table 1; information regarding type, dose, adherence and history of antidepressant or anxiolytic medications use are expected among others.

(2) The interaction of exercise with antidepressant/anxiolytic medications needs to be tested in clinical settings by undertaking: (a) four-armed RCTs (exercise vs. medication vs. exercise+medication vs. placebo medication) with anxiety or depression as primary outcome; (b) two-armed RCTs involving planned stratification analyses according to antidepressant/anxiolytic participants' use during intervention (Kent \& Hayward, 2007). New knowledge may be obtained by using several strategies of stratification: stratified randomization according to antidepressant/anxiolytic use at baseline, a posteriori stratification according to antidepressant/anxiolytic use as a time-varying variable in the course of the intervention; molecule type, dosage. The examination of dose-effect relationships as secondary analyses may also highlight the interaction of exercise with medications. Trial designers should account for sample size inflation due to stratification by including appropriate numbers of subjects to allow sufficient statistical power (Green \& Byar, 1978).

(3) N-of-1 (single-patient) randomized trials could be usefully designed to facilitate a direct estimation of individual medication/exercise effects. An n-of-1 RCT is "a crossover experiment conducted with a single participant who acts as their own control" (Naughton \& Johnston, 2014). These trials are regarded as the highest level of evidence for individual treatment decisions, over and above systematic reviews of RCTs that only drive conclusions for groups of individuals (Guyatt et al., 2000). The multiple-period crossover experiments comparing the two treatments (i.e., antidepressant and exercise) within individual patients could provide valuable knowledge about possible synergistic or antagonist effect and sequential or concurrent 
delivery. The design can be made more stringent by adding a wash-out period (see details in Duan, Kravitz, \& Schmid, 2013)

(4) Repeated objective measures of physical activity (with accelerometer) after antidepressant or anxiolytic prescription may be considered to explore exercise-related behavioral effects of these drugs. Either observational studies recording exercise behavior evolution in "natural" settings following antidepressant/anxiolytic prescription, or clinical trials assessing the effect of medication prescription (intervention) on exercise behavior (outcome) would be of interest.

(5) A two arm RCT based on a stepped-care approach could compare physical activity self-help program vs. antidepressant as first-line treatment for adults with depressive/anxiety disorders. If these less intensive treatments fail to meet clinical depression or anxiety reduction/remission, supervised exercise intervention could be prescribed with more intensive treatment goals.

(6) Finally, a meta-analysis of individual participant data could be carried out by pooling data from exercise based RCTs that collected information on antidepressant or anxiolytics (e.g., description of use at baseline) (Riley, Lambert, \& Abo-Zaid, 2010). Comparison of exercise efficacy across groups of individuals with or without medications could highlight the exercise-drug interaction.

\section{Conclusion}

Antidepressant and anxiolytics drugs may confound our understanding of the effects of exercise on anxiety and depression which may occur through biological pathways (some may act synergistically while others may be antagonistic), behavioural pathways (with indications of poorer exercise adherence for drug users), and indirect pathways (driven by deteriorated health status affecting the exercise capabilities of medication users). Therefore, the use of antidepressant or anxiolytic medications needs to be carefully considered in future studies assessing the effects of exercise on anxiety or depression. Future trials should provide data regarding the use of antidepressant or anxiolytic medications at baseline, and include a stratified randomization and statistically control for antidepressant/anxiolytic use. Further rigorous studies which assess the interaction of exercise with anxiolytics and/or antidepressants (e.g., four-armed RCTs with exercise+SSRI, exercise+placebo, exercise, SSRI) on anxiety and depression are required. 


\section{References}

Armstrong, K., \& Edwards, H. (2003). The effects of exercise and social support on mothers reporting depressive symptoms: a pilot randomized controlled trial. International Journal of Mental Health Nursing, 12(2), 130-138.

Armstrong, K., \& Edwards, H. (2004). The effectiveness of a pram-walking exercise programme in reducing depressive symptomatology for postnatal women. International Journal of Nursing Practice, 10(4), 177-194. doi.org/10.1111/j.1440-172X.2004.00478.x

Atlantis, E., Sullivan, T., Sartorius, N., \& Almeida, O. P. (2012). Changes in the prevalence of psychological distress and use of antidepressants or anti-anxiety medications associated with comorbid chronic diseases in the adult Australian population, 2001-2008. Australian and New Zealand Journal of Psychiatry, 46(5), 445-456. doi:10.1177/0004867411433218

Azzone, V., Frank, R. G., Pakes, J. R., Earle, C. C., \& Hassett, M. J. (2009). Behavioral health services for women who have breast cancer. Journal of Clinical Oncology, 27(5), 706-712. doi:10.1200/JCO.2008.16.3006

Bernard, P., Ninot, G., Bernard, P. L., Picot, M. C., Jaussent, A., Tallon, G., \& Blain, H. (2015). Effects of a six-month walking intervention on depression in inactive post-menopausal women: a randomized controlled trial. Aging \& Mental Health, 9(6), 485-492. doi:10.1080/13607863.2014.948806

Blumenthal, J. A., Sherwood, A., Babyak, M. A., Watkins, L. L., Smith, P. J., Hoffman, B. M., ... Hinderliter, A. L. (2012a). Exercise and pharmacological treatment of depressive symptoms in patients with coronary heart disease: results from the UPBEAT study. Journal of the American College of Cardiology, 60(12), 1053-1063. doi:10.1016/j.jacc.2012.04.040

Blumenthal, J. A., Babyak, M. A., O’Connor, C., Keteyian, S., Landzberg, J., Howlett, J., ... Whellan, D. J. (2012b). Effects of exercise training on depressive symptoms in patients with chronic heart failure: the HF-ACTION randomized trial. JAMA, 308(5), 465-474. http://doi.org/10.1001/jama.2012.8720

Blumenthal, J. A., Sherwood, A., Babyak, M. A., Watkins, L. L., Waugh, R., Georgiades, A., ... Hinderliter, A. (2005). Effects of exercise and stress management training on markers of cardiovascular risk in patients with ischemic heart disease: a randomized controlled trial. JAMA, 293(13), 1626-1634. doi:10.1001/jama.293.13.1626 
Blumenthal, J. A., Babyak, M. A., Moore, K. A., Craighead, W. E., Herman, S., Khatri, P., ... Krishnan, K. R. (1999). Effects of exercise training on older patients with major depression. Archives of Internal Medicine, 159(19), 2349-2356.

Blumenthal, J. A., Babyak, M. A., Doraiswamy, P. M., Watkins, L., Hoffman, B. M., Barbour, K. A., ... Sherwood, A. (2007). Exercise and pharmacotherapy in the treatment of major depressive disorder. Psychosomatic Medicine, 69(7), 587-596. doi:10.1097/PSY.0b013e318148c19a

Bombardier, C. H., Ehde, D. M., Gibbons, L. E., Wadhwani, R., Sullivan, M. D., Rosenberg, D. E., \& Kraft, G. H. (2013). Telephone-based physical activity counseling for major depression in people with multiple sclerosis. Journal of Consulting and Clinical Psychology, 81(1), 89-99. http://doi.org/10.1037/a0031242

Breitbart, W. (2011). Do antidepressants reduce the effectiveness of tamoxifen?. Psycho-Oncology, 20(1), 1-4. doi:10.1002/pon.1872

Brenes, G. A., Williamson, J. D., Messier, S. P., Rejeski, W. J., Pahor, M., Ip, E., \& Penninx, B. W. J. H. (2007). Treatment of minor depression in older adults: a pilot study comparing sertraline and exercise. Aging \& Mental Health, 11(1), 61-68. http://doi.org/10.1080/13607860600736372

Broocks, A., Bandelow, B., Pekrun, G., George, A., Meyer, T., Bartmann, U., ... Rüther, E. (1998). Comparison of aerobic exercise, clomipramine, and placebo in the treatment of panic disorder. The American Journal of Psychiatry, 155(5), 603-609.

Carayol, M., Bernard, P., Boiché, J., Riou, F., Mercier, B., Cousson-Gélie, F., ... Ninot, G. (2013). Psychological effect of exercise in women with breast cancer receiving adjuvant therapy: what is the optimal dose needed? Annals of Oncology, 24(2), 291-300. doi:10.1093/annonc/mds342

Carayol, M., Delpierre, C., Bernard, P., \& Ninot, G. (2015). Population-,intervention-, methodology-related characteristics of clinical trials impact exercise efficacy during adjuvant therapy for breast cancer: a meta-regression analysis. Psycho-Oncology. doi: 10.1002/pon.3727

Chalder, M., Wiles, N. J., Campbell, J., Hollinghurst, S. P., Haase, A. M., Taylor, A. H., ... Lewis, G. (2012). Facilitated physical activity as a treatment for depressed adults: randomised controlled trial. BMJ , 344 , e2758.

Chen, J. M. (2013). The neurobiology of depression and physical exercise. In Routledge Handbook of Physical Activity and Mental Health (pp. 169-183). Routledge. 
Chu, I.-H., Buckworth, J., Kirby, T. E., \& Emery, C. F. (2009). Effect of exercise intensity on depressive symptoms in women. Mental Health and Physical Activity, 2(1), 37-43. http://doi.org/10.1016/j.mhpa.2009.01.001

Cooney, G. M., Dwan, K., Greig, C. A., Lawlor, D. A., Rimer, J., Waugh, F. R., ... Mead, G. E. (2013). Exercise for depression. The Cochrane Database of Systematic Reviews, 9, CD004366. http://doi.org/10.1002/14651858.CD004366.pub6

Celano, C. M., Freudenreich, O., Fernandez-Robles, C., Stern, T. A., Caro, M. A., \& Huffman, J. C. (2011). Depressogenic effects of medications: a review. Dialogues in Clinical Neuroscience, 13(1), 109-125.

Craft, L. L., Freund, K. M., Culpepper, L., \& Perna, F. M. (2007). Intervention Study of Exercise for Depressive Symptoms in Women. Journal of Women's Health, 16(10), 1499-1509. doi:10.1089/jwh.2007.0483

Coventry, P. A., Bower, P., Keyworth, C., Kenning, C., Knopp, J., Garrett, C., ... Dickens, C. (2013). The Effect of Complex Interventions on Depression and Anxiety in Chronic Obstructive Pulmonary Disease: Systematic Review and Meta-Analysis. PLoS ONE, 8(4), e60532. doi:10.1371/journal.pone.0060532

Coyne, J. C., Palmer, S. C., Shapiro, P. J., Thompson, R., \& DeMichele, A. (2004). Distress, psychiatric morbidity, and prescriptions for psychotropic medication in a breast cancer waiting room sample. General Hospital Psychiatry, 26(2), 121-128. doi:10.1016/j.genhosppsych.2003.08.012

Dalgas, U., Stenager, E., Sloth, M., \& Stenager, E. (2014). The effect of exercise on depressive symptoms in multiple sclerosis based on a meta-analysis and critical review of the literature. European Journal of Neurology,. doi:10.1111/ene.12576

Desharnais, R., Jobin, J., Côté, C., Lévesque, L., \& Godin, G. (1993). Aerobic exercise and the placebo effect: a controlled study. Psychosomatic Medicine, 55(2), 149-154.

Dunn, A. L., Trivedi, M. H., Kampert, J. B., Clark, C. G., \& Chambliss, H. O. (2005). Exercise treatment for depression: efficacy and dose response. American Journal of Preventive Medicine, 28(1), 1-8. doi:10.1016/j.amepre.2004.09.003 
Duan, N., Kravitz, R. L., \& Schmid, C. H. (2013). Single-patient (n-of-1) trials: a pragmatic clinical decision methodology for patient-centered comparative effectiveness research. Journal of Clinical Epidemiology, 66(8, Supplement), S21-S28. doi:10.1016/j.jclinepi.2013.04.006

Ekkekakis, P. (2015). Honey, I shrunk the pooled SMD! Guide to critical appraisal of systematic reviews and meta-analyses using the Cochrane review on exercise for depression as example. Mental Health and Physical Activity, 8, 21-36. http://doi.org/10.1016/j.mhpa.2014.12.001

Foley, L. S., Prapavessis, H., Osuch, E. A., De Pace, J. A., Murphy, B. A., \& Podolinsky, N. J. (2008). An examination of potential mechanisms for exercise as a treatment for depression: A pilot study. Mental Health and Physical Activity, 1(2), 69-73. http://doi.org/10.1016/j.mhpa.2008.07.001

Gary, R. A., Dunbar, S. B., Higgins, M. K., Musselman, D. L., \& Smith, A. L. (2010). Combined exercise and cognitive behavioral therapy improves outcomes in patients with heart failure. Journal of Psychosomatic Research, 69(2), 119-131. http://doi.org/10.1016/j.jpsychores.2010.01.013

Green, S. B., \& Byar, D. P. (1978). The effect of stratified randomization on size and power of statistical tests in clinical trials. Journal of Chronic Diseases, 31(6-7), 445-454. doi:10.1016/0021-9681(78)90008-5

Guyatt, G. H., Haynes, R. B., Jaeschke, R. Z., Cook, D. J., Green, L., Naylor, C. D., ... Richardson, W. S. (2000). Users' Guides to the Medical Literature: XXV. Evidence-based medicine: principles for applying the Users' Guides to patient care. Evidence-Based Medicine Working Group. JAMA, 284(10), 1290-1296.

Herman, S., Blumenthal, J. A., Babyak, M., Khatri, P., Craighead, W. E., Krishnan, K. R., \& Doraiswamy, P. M. (2002). Exercise therapy for depression in middle-aged and older adults: predictors of early dropout and treatment failure. Health Psychology, 21(6), 553-563.

Herring, M. P., O'Connor, P. J., \& Dishman, R. K. (2010). The effect of exercise training on anxiety symptoms among patients: a systematic review. Archives of Internal Medicine, 170(4), 321-331. doi:10.1001/archinternmed.2009.530

Herring, M. P., Puetz, T. W., O'Connor, P. J., \& Dishman, R. K. (2012). Effect of exercise training on depressive symptoms among patients with a chronic illness: a systematic review and meta-analysis of randomized controlled trials. Archives of Internal Medicine, 172(2), 101-111. doi:10.1001/archinternmed.2011.696 
Imayama, I., Alfano, C. M., Mason, C., Wang, C., Duggan, C., Campbell, K. L., ... McTiernan, A. (2013). Weight and metabolic effects of dietary weight loss and exercise interventions in postmenopausal antidepressant medication users and non-users: A randomized controlled trial. Preventive Medicine, 57(5), 525-532. doi:10.1016/j.ypmed.2013.07.006

Jette, A. M., Rooks, D., Lachman, M., Lin, T. H., Levenson, C., Heislein, D., ... Harris, B. A. (1998). Homebased resistance training: predictors of participation and adherence. The Gerontologist, 38(4), 412-421.

Kent, D. M., \& Hayward, R. A. (2007). Limitations of applying summary results of clinical trials to individual patients: the need for risk stratification. JAMA, 298(10), 1209-1212. doi:10.1001/jama.298.10.1209

Labotz, M., Wolff, T. K., Nakasone, K. T., Kimura, I. F., Hetzler, R. K., \& Nichols, A. W. (2006). Selective serotonin reuptake inhibitors and rhabdomyolysis after eccentric exercise. Medicine and Science in Sports and Exercise, 38(9), 1539-1542. doi:10.1249/01.mss.0000227643.06478.c6

Laustsen, S., Hjortdal, V. E., \& Petersen, A. K. (2013). Predictors for not completing exercise-based rehabilitation following cardiac surgery. Scandinavian Cardiovascular Journal, 47(6), 344-351. doi:10.3109/14017431.2013.859295

Liberati, A., Altman, D. G., Tetzlaff, J., Mulrow, C., Gøtzsche, P. C., loannidis, J. P. A., ... Moher, D. (2009). The PRISMA Statement for Reporting Systematic Reviews and Meta-Analyses of Studies That Evaluate Health Care Interventions: Explanation and Elaboration. PLoS Medicine, 6(7), e1000100. http://doi.org/10.1371/journal.pmed.1000100

Marlatt, M. W., Lucassen, P. J., \& van Praag, H. (2010). Comparison of neurogenic effects of fluoxetine, duloxetine and running in mice. Brain Research, 1341, 93-99. doi:10.1016/j.brainres.2010.03.086

Marzolini, S., Brooks, \& Oh, P. (2008). Sex differences in completion of a 12-month cardiac rehabilitation programme: an analysis of 5922 women and men. European Journal of Cardiovascular Prevention and Rehabilitation, 15(6), 698-703. doi:10.1097/HJR.0b013e32830c1ce3

Martinsen, E. W., Hoffart, A., \& Solberg, O. (1989). Comparing aerobic with nonaerobic forms of exercise in the treatment of clinical depression: a randomized trial. Comprehensive Psychiatry, 30(4), 324-331.

Martinsen, E. W., Medhus, A., \& Sandvik, L. (1985). Effects of aerobic exercise on depression: a controlled study. BMJ, 291(6488), 109-109. doi:10.1136/bmj.291.6488.109 
Mather, A. S., Rodriguez, C., Guthrie, M. F., McHarg, A. M., Reid, I. C., \& McMurdo, M. E. T. (2002). Effects of exercise on depressive symptoms in older adults with poorly responsive depressive disorder: randomised controlled trial. The British Journal of Psychiatry, 180, 411-415.

Martiny, K., Refsgaard, E., Lund, V., Lunde, M., Sørensen, L., Thougaard, B., ... Bech, P. (2012). A 9-week randomized trial comparing a chronotherapeutic intervention (wake and light therapy) to exercise in major depressive disorder patients treated with duloxetine. The Journal of Clinical Psychiatry, 73(9), 1234-1242. http://doi.org/10.4088/JCP.11m07625

Mota-Pereira, J., Silverio, J., Carvalho, S., Ribeiro, J. C., Fonte, D., \& Ramos, J. (2011). Moderate exercise improves depression parameters in treatment-resistant patients with major depressive disorder. Journal of Psychiatric Research, 45(8), 1005-1011. doi:10.1016/j.jpsychires.2011.02.005

Mura, G., Moro, M. F., Patten, S. B., \& Carta, M. G. (2014). Exercise as an add-on strategy for the treatment of major depressive disorder: a systematic review. CNS Spectrums, 19(6), 496-508.

Naughton, F., \& Johnston, D. (2014). A starter kit for undertaking n-of-1 trials. European Health Psychologist, 16(5), 196-205.

Neidig, J. L., Smith, B. A., \& Brashers, D. E. (2003). Aerobic exercise training for depressive symptom management in adults living with HIV infection. The Journal of the Association of Nurses in AIDS Care, 14(2), 30-40.

Ng, C. G., Boks, M. P., Smeets, H. M., Zainal, N. Z., \& de Wit, N. J. (2013). Prescription patterns for psychotropic drugs in cancer patients; a large population study in the Netherlands. PsychoOncology, 22(4), 762-767. doi:10.1002/pon.3056

Perraton, L. G., Kumar, S., \& Machotka, Z. (2010). Exercise parameters in the treatment of clinical depression: a systematic review of randomized controlled trials. Journal of Evaluation in Clinical Practice, 16(3), 597-604. doi:10.1111/j.1365-2753.2009.01188.x

Pilu, A., Sorba, M., Hardoy, M. C., Floris, A. L., Mannu, F., Seruis, M. L., ... Carta, M. G. (2007). Efficacy of physical activity in the adjunctive treatment of major depressive disorders: preliminary results. Clinical Practice and Epidemiology in Mental Health, 3, 8. http://doi.org/10.1186/1745-0179-3-8

Piette, J. D., Richardson, C., Himle, J., Duffy, S., Torres, T., Vogel, M., ... Valenstein, M. (2011). A randomized trial of telephonic counseling plus walking for depressed diabetes patients. Medical 
Care, 49(7), 641-648. http://doi.org/10.1097/MLR.0b013e318215d0c9

Rethorst, C. D., Wipfli, B. M., \& Landers, D. M. (2010). The antidepressive effects of exercise: a metaanalysis of randomized trials. Sports Medicine, 39(6), 491-511.

Riley, R. D., Lambert, P. C., \& Abo-Zaid, G. (2010). Meta-analysis of individual participant data: rationale, conduct, and reporting. BMJ, 340, c221.

Robertson, R., Robertson, A., Jepson, R., \& Maxwell, M. (2012). Walking for depression or depressive symptoms: A systematic review and meta-analysis. Mental Health and Physical Activity, 5(1), 66-75. http://doi.org/10.1016/j.mhpa.2012.03.002

Russo-Neustadt, A., Beard, R. C., \& Cotman, C. W. (1999). Exercise, antidepressant medications, and enhanced brain derived neurotrophic factor expression. Neuropsychopharmacology, 21(5), 679-682. doi:10.1016/S0893-133X(99)00059-7

Schuch, F. B., Vasconcelos-Moreno, M. P., Borowsky, C., \& Fleck, M. P. (2011). Exercise and severe depression: preliminary results of an add-on study. Journal of Affective Disorders, 133(3), 615-618. http://doi.org/10.1016/j.jad.2011.04.030

Sevick, M. A., Trauth, J. M., Ling, B. S., Anderson, R. T., Piatt, G. A., Kilbourne, A. M., \& Goodman, R. M. (2007). Patients with Complex Chronic Diseases: perspectives on supporting self-management. Journal of General Internal Medicine, 22 Suppl 3, 438-444. doi:10.1007/s11606-007-0316-z

Stonerock, G. L., Hoffman, B. M., Smith, P. J., \& Blumenthal, J. A. (2015). Exercise as Treatment for Anxiety: Systematic Review and Analysis. Annals of Behavioral Medicine. doi:10.1007/s12160-014-9685-9

Tobi, P., Estacio, E. V., Yu, G., Renton, A., \& Foster, N. (2012). Who stays, who drops out? Biosocial predictors of longer-term adherence in participants attending an exercise referral scheme in the UK. BMC Public Health, 12, 347. doi:10.1186/1471-2458-12-347

Tu, R.-H., Zeng, Z.-Y., Zhong, G.-Q., Wu, W.-F., Lu, Y.-J., Bo, Z.-D., .. Yao, L.-M. (2014). Effects of exercise training on depression in patients with heart failure: a systematic review and meta-analysis of randomized controlled trials: Effects of exercise training on depression in heart failure: a systematic review. European Journal of Heart Failure, 16(7), 749-757. doi:10.1002/ejhf.101

Veale, D., Le Fevre, K., Pantelis, C., de Souza, V., Mann, A., \& Sargeant, A. (1992). Aerobic exercise in the adjunctive treatment of depression: a randomized controlled trial. Journal of the Royal Society of Medicine, 85(9), 541-544. 
Wipfli, B., Landers, D., Nagoshi, C., \& Ringenbach, S. (2009). An examination of serotonin and psychological variables in the relationship between exercise and mental health. Scandinavian Journal of Medicine \& Science in Sports. 2011 Jun;21(3):474-81. doi:10.1111/j.1600-0838.2009.01049.x

Wedekind, D., Broocks, A., Weiss, N., Engel, K., Neubert, K., \& Bandelow, B. (2010). A randomized, controlled trial of aerobic exercise in combination with paroxetine in the treatment of panic disorder. The World Journal of Biological Psychiatry, 11(7), 904-913. doi:10.3109/15622975.2010.489620

Williams, C. L., \& Tappen, R. M. (2008). Exercise training for depressed older adults with Alzheimer's disease. Aging \& Mental Health, 12(1), 72-80. 
Table 1

Patient, Intervention, Comparison criteria useful for design and report of trials assessing the effects of exercise on depression outcomes (example with antidepressant)

\begin{tabular}{|c|c|c|c|}
\hline & $\begin{array}{c}\text { Population } \\
\text { (inclusion or controlled } \\
\text { criteria) }\end{array}$ & Interventions & Comparison \\
\hline$A D$ & $\begin{array}{l}\text { Antidepressant use } \\
\text { Duration of antidepressant } \\
\text { treatment } \\
\text { Patients proportion of: } \\
\text {-Drug naive } \\
\text {-Poor responder (e.g., } \\
\text { antidepressant for at least } 6 \\
\text { weeks without evidence of } \\
\text { clinical response prior trial, } \\
\text { (Mather et al., 2002)) } \\
\text {-Resistant (e.g., participant fail } \\
\text { to reach symptomatic } \\
\text { remission after at least } 2 \\
\text { adequate antidepressant trials, } \\
\text { (Motta-Pereira et al., 2011)) }\end{array}$ & $\begin{array}{l}\text { Molecule type: } \\
\text {-Selective serotonin reuptake inhibitors } \\
\text { (e.g., fluoxetine, sertraline, escitalopram) } \\
\text {-Serotonin norepinephrine reuptake } \\
\text { inhibitors (e.g., venlafaxine, duloxetine) } \\
\text {-Monoamine oxidase inhibitors (e.g., } \\
\text { phenelzine, tranylcypromine) } \\
\text {-Tricyclic antidepressant (e.g., } \\
\text { nortriptyline) } \\
\text { Dose (starting or usual) } \\
\text { Therapeutic delay effect } \\
\text { Minimum washout period } \\
\text { Medication adherence } \\
\text { Sequential or concurrent delivery }\end{array}$ & $\begin{array}{l}\text { Antidepressant } \\
\text { placebo }\end{array}$ \\
\hline Ex/PA & $\begin{array}{l}\text { PA level: } \\
\text {-Active } \\
\text {-Inactive (e.g., < } 9.4 \text { on the } \\
\text { PAQE, (Bernard et al., } \\
\text { 2015)) } \\
\text {-Sedentary }\end{array}$ & $\begin{array}{l}\text { Nature (e.g., walking, (Bernard et al., } \\
\text { 2015)) } \\
\text { Combination (e.g., resistance + } \\
\text { endurance) } \\
\text { Dose (e.g., } 17.5 \mathrm{kcal} / \mathrm{kg} / \text { week with } 3 \\
\text { sessions/week, (Dunn et al., 2005)) } \\
\text { Intensity (e.g., moderate, graduate) } \\
\text { Context: } \\
\text {-Home based } \\
\text {-Supervised } \\
\text {-Mixed } \\
\text {-Outdoor } \\
\text { Sequential or concurrent delivery } \\
\text { Acute versus chronic exercise } \\
\text { Exercise adherence }\end{array}$ & $\begin{array}{l}\text { Exercise } \\
\text { placebo (e.g., } \\
\text { expectancy } \\
\text { modification } \\
\text { intervention, } \\
\text { (Desharnais et } \\
\text { al., 1993) }\end{array}$ \\
\hline Other & $\begin{array}{l}\text { Presence of chronic disease } \\
\text { (e.g., heart failure, (Blumenthal } \\
\text { et al., 2012a)) } \\
\text { Presence of depressive } \\
\text { disorders: } \\
\text {-Major Depressive Disorder } \\
\text {-Dysthymia } \\
\text {-Elevated depressive } \\
\text { disorders }\end{array}$ & $\begin{array}{l}\text { Expectancy/ beliefs regarding exercise } \\
\text { (e.g., Blumenthal et al., 2007) } \\
\text { Study context: } \\
\text {-Primary care } \\
\text {-Psychiatry (in- or outpatients) } \\
\text {-Rehabilitation } \\
\text { Potential depressogenic treatments (e.g., } \\
\text { Celano et al., 2011) }\end{array}$ & \\
\hline
\end{tabular}

Notes. $\mathrm{AD}=$ Antidepressant, $\mathrm{PAQE}=$ Physical activity questionnaire for elderly, $\mathrm{Ex}=$ Exercise, $\mathrm{PA}$ $=$ Physical Activity 